\title{
Uma análise da contextualização na perspectiva CTSA sob a ótica do professor de química
}

\author{
An analysis of context in the perspective STSE from the view of chemistry teacher \\ Miguel Antonio Favila e Martha Adaime \\ Universidade Federal de Santa Maria
}

\section{Resumo}

A abordagem do ensino de química contextualizado no enfoque CTSA é um ponto complexo e significativo que orienta sujeitos para a sociedade. Essa proposta objetivou sondar o perfil dos professores, suas condições de trabalho, e suas concepções sobre a contextualização. A pesquisa foi realizada mediante aplicação de um questionário semiestruturado, em 18 professores da rede pública estadual e privada da cidade de Santa Maria, RS. Na análise dos dados, pode-se inferir que os professores são do sexo feminino, com mais de cinco anos de atuação profissional, com especialização, trabalham em uma escola, com mais de duas horas para planejamento das aulas e fazem curso de capacitação uma vez por ano. A maioria delas associa a contextualização com o dia-a-dia. As dificuldades encontradas pela maioria são a falta de tempo e motivação por parte dos alunos.

Palavras-chave: Contextualização, CTSA, perfil do professor.

\begin{abstract}
The proposal of teaching chemistry in the STSE context is a meaningful and complex detail which guides people to the society. This suggestion aimed to bring in teachers' profile, their working conditions, and their views in the context. The research was held through the applying a semi-structured questionnaire, to 18 public and private school's teachers of the city of Santa Maria, RS. In the data analysis, which can induce that teachers are female, more than five years of professional experience, with specialization, only work in one school, with more than two hours per lesson for planning it and make capacity course once a year. Most of the teachers connect the context with the daily. The difficulties founded by them were having no time and no motivation among the students.
\end{abstract}

Keywords: Contextualization, STSE, teacher profile. 


\section{INTRODUCCÃO}

Vivemos na era da globalização, com a tecnologia facilitando o dia-a-dia das pessoas. Contudo, se por um lado as máquinas estão à disposição para os mais variados fins, por outro, surgem novas demandas de energia e matéria -prima, e consequentemente o agravamento das questões ambientais (Ricardo, 2007). Nesta perspectiva, uma visão crítica da sociedade e dos acontecimentos atuais requer conhecimento sobre ciência e tecnologia, na tomada de decisões que ultrapassem o senso comum. Desse modo, Santos (2008) contextualiza os efeitos nocivos desse avanço tecnológico exemplificando a maximização dos lucros e minimização dos custos, a racionalidade do sistema tecnológico que prioriza o capital sobre os valores humanos.

Dessa forma, novos conhecimentos científicos e tecnológicos são apontados a todo o momento nos meios de comunicação. Para Alarcão (2002), estamos na época da informação que foi inicialmente denominada de sociedade da informação e logo depois alterada para sociedade da informação e do conhecimento e mais recentemente intitula-se sociedade da aprendizagem. Nesta vertente, o ensino precisa ajustar-se ao novo, ou seja, aproximar os currículos com as situações vividas pelos alunos, adequandose a esses novos parâmetros numa perspectiva da ciência, tecnologia, sociedade e ambiente - CTSA. Neste aspecto, a contextualização no entendimento de Pérez (1995) ocorre a partir de práticas problematizadoras, que oferece ao aluno uma visão de que os conhecimentos científicos aprendidos fazem-se presentes no seu cotidiano. A escola está inserida neste mundo de mudanças, visto que o perfil dos alunos também mudou, e a escola precisa se adequar a essas transformações da era da miscigenação da informação, da ciência, da economia e da política.

No entanto, ainda muitas escolas priorizam a ênfase na memorização de conteúdos isolados, exposto por professores da área de ciências seguindo o livro didático. Antes de tudo, é preciso entender em qual segmento insere-se esse aluno, qual sua tradição cultural, étnica e religiosa, quais os meios de comunicação social que ele participa, e além de tudo, permitir que a sua visão de mundo, ou seja, suas vivências possam brotar em sala de aula, capacitando-o a enfrentar as situações do cotidiano (ZABALA,1998).

\section{I Primórdios da contextualiza-ção}

O princípio de contextualização do ensino, segundo Kato (2011), não é recente e não se originou dos documentos oficiais das propostas curriculares dos Parâmetros Curriculares Nacionais - PCN. Propostas anteriores já o mencionavam, entretanto, de outras formas ou termos, na intenção de suprir a necessidade de um ensino fragmentado, muito formal e isolado, que não contemplava os contextos, e, portanto, distantes do mundo vivido pelos alunos. A reformulação do ensino médio no Brasil, estabelecida pela Lei de Diretrizes e Bases da Educação Nacional - LDBEN de 1996, regulamentada em 1998 pelas Diretrizes do Conselho Nacional de Educação e pelos Parâmetros Curriculares Nacionais procurou atualizar a educação brasileira. Para isso, intensificou uma democratização social e cultural mais pronunciada, visto que, ocorreu uma ampliação da parcela da juventude que completa a educação básica (BRASIL, 2002). Nesse aspecto, preencheria os desafios impostos por processos globais, que têm excluído da vida econômica os trabalhadores não qualificados.

$\mathrm{O}$ ensino contextualizado teve sua origem oficial com o Movimento Ciência Tecnologia e Sociedade - CTSA, na década de setenta, devido o crescente desenvolvimento da ciência e tecnologia. Mais recentemente na década de noventa, a preocupação com as questões ambientais e suas relações com a Ciência, Tecnologia e Sociedade, fez surgir o movimento Ciência, Tecnologia e Sociedade e Ambiente - CTSA (MARCONDES, 2009). Para Müenchen (2007), o movimento CTS resgata a matriz teórico-filosófica, com a retomada nas participações de decisões em temas sociais que envolvem a ciência e a tecnologia. Já na concepção de Bazzo (1998) o cidadão merece entender a ciência e a tecnologia com suas implicações e consequências, para poder ser sujeito participante nas decisões de ordem política, social e ambiental, que certamente influenciarão o seu futuro e de seus descendentes.

A reforma do ensino médio, definida nos Parâmetros Curriculares Nacionais para o Ensino Médio - PCNEM desenvolveu os conteúdos escolares de modo contextualizado, e estruturado sobre os eixos da interdisciplinaridade e da contextualização. Em 2002, a proposta dos PCN+ complementou a anterior, com atribuição de "significados aos conteúdos" (BRASIL, 2002). Os professores na visão de Moreira (1995) esperam que seus alunos captem ou incorporem em sua cognição, os significados cientificamente aceitos ou contextualmente compartilhados, interagindo 
com eles e trocando significados. No entendimento de Kato (2011) o sujeito é interativo, e nessa troca com outros sujeitos, experiências, hábitos, atitudes e valores que internaliza o conhecimento. É através da internalização das construções sociais, históricas e culturais, pelo intermédio da interação social, que o sujeito se desenvolve cognitivamente. Assim, ele enfatiza que os significados de palavras e gestos são construídos socialmente e assim são contextuais (MOREIRA, 2009).

A contextualização valoriza a experiência do estudante e o contexto onde ele está inserido e onde atuará como cidadão ativo na sociedade. Neste aspecto, Y C. Forghieri define vivência como: "a percepção que o ser humano tem de suas próprias experiências, atribuindo-lhes significados que, com maior ou menor intensidade, sempre estão acompanhados de alguns sentimentos de agrado ou desagrado" (FERREIRA, 2010). Muitos professores detêm concepções errôneas sobre aprendizagem, tratando seus alunos como uma folha de papel em branco pronta para ser preenchida, isto é, alguns desconsideram seus conhecimentos prévios, outros suas vivências que fazem parte desse complexo processo de aprendizagem (FREIRE, 2002).

Se pensarmos na contextualização em seu sentido mais amplo, Chassot et al. (1993) defende o emprego de um ensino de Química como meio de educação para a vida relacionando o conteúdo do aprendizado em sala de aula e o dia-a-dia dos alunos, formando assim o aluno-cidadão capaz de refletir, compreender, discutir e agir sobre a sociedade que está em sua volta. O enfoque CTSA na aprendizagem, de acordo com Auler (2009) deve ter como ponto de partida "situações-problemas" aplicados à contextos reais. Neste mesmo entendimento, Auler (2001) complementa que a integração entre CTSA no ensino de ciências, representa uma tentativa de formar cidadãos científica e tecnologicamente alfabetizados, capazes de tomar decisões informadas e desenvolver ações responsáveis.

Generalizando em poucas palavras, a contextualização é agregar o conhecimento com sua origem e com a sua aplicação. A aprendizagem torna-se mais prazerosa e interessante, tanto para alunos e professores, quando se inova em sala de aula e proporciona ao aluno observar, debater e formar opiniões sobre os conceitos e conteúdos aprendidos.

Diante disso, requer motivação para aprender o novo, que pode ser viabilizada pela criatividade do educador na construção do conhecimento com situações simples do cotidiano, estabelecendo o diálogo em sala de aula entre alunos e professores. Dentro desta perspectiva, este artigo consiste em apresentar e discutir os resultados encontrados sobre as concepções dos professores de química, referente à contextualização sob a ótica CTSA e, averiguar os prováveis obstáculos que os impossibilitam de contextualizar.

\section{DELINEAMENTO METODOLÓGICO}

O presente estudo caracterizou-se como uma pesquisa aplicada e descritiva, devido ter contribuído teoricamente com novos fatos para o planejamento de novas pesquisas, bem como, pelo contato direto com as pessoas, na sondagem de dados sociais, demográficos, opiniões, atitudes ou crenças de uma população (ZANELLA, 2009). O trabalho baseou-se numa abordagem quantitativa, com amostra composta de 13 professores de escolas públicas estaduais, selecionadas de cada região da cidade de Santa Maria-RS, e de 5 professores de escolas particulares, que foram autorizados pela escola para participar da pesquisa.

$\mathrm{O}$ instrumento utilizado para a coleta de dados foi o semiestruturado, com questões abertas e fechadas, aplicado nos meses de abril e maio de 2013. A primeira parte foi definida com questões fechadas direcionada ao perfil dos participantes, versando sobre os seguintes tópicos: sexo, nível de escolaridade, vínculo empregatício, frequência da realização de curso de aperfeiçoamento, tempo de atuação no magistério, carga-horária semanal, número de escolas em que trabalham preconizadas por Guimarães (2006). A segunda parte consistiu-se de questões abertas possibilitando maior liberdade por parte dos respondentes. As respostas foram categorizadas de forma indutiva por classes de palavras, gerando categorias emergentes conforme Bardin (2004). Abordou-se as concepções dos professores de química sobre o conceito de contextualização, tal como as estratégias e dificuldades para contextualizar em sala de aula.

\section{RESULTADOS E DISCUSSÃO}

Nesta seção, apresentaremos e discutiremos os resultados do questionário semiestruturado aplicado aos professores das escolas estaduais e particulares. As primeiras questões referiam-se ao perfil dos 18 professores participantes, $78 \%$ eram do sexo feminino e $22 \%$ do sexo masculino, em 
consonância com os dados do senso do INEP/ MEC 2009, que evidenciaram que $64,4 \%$ dos professores do ensino médio eram do sexo feminino em oposição a $35,6 \%$ do sexo masculino. Esse dado sugestiona que a menor incidência de professores do sexo masculino na educação básica, está relacionada à inexistência de uma política salarial efetiva e atraente. A respeito do período de conclusão da formação acadêmica, acerca de $66 \%$ dos professores concluíram a graduação em química no período compreendido entre os anos de 1993 a 2005. O tempo de atuação na carreira, variou entre 5 e 20 anos de magistério para a maioria dos participantes (44\%) e estão de acordo com o dados de Silva et al (2009) que também encontrou o tempo de 5 e 33 anos de atuação na carreira do magistério. Ficou demonstrado que a maioria dos entrevistados não era iniciante na profissão e que $8(44,4 \%)$ dos professores apresentam a carga-horária semanal de $40 \mathrm{hs}$ e 7 (38,8\%) a carga-horária de $20 \mathrm{hs}$, e apenas $1 \mathrm{com}$ a carga-horária de $60 \mathrm{hs}$. Quanto ao vínculo empregatício $8(44,4 \%)$ professores pertencem ao quadro efetivo do estado e $5(38,4 \%)$ professores são contratados do estado, perfazendo um percentual de $82,8 \%$ em escolas estaduais. Esse resultado está em consonância com a base de dados do Censo Escolar da Educação Básica de 2009, que menciona o percentual de $76,5 \%$ dos professores atuarem em escolas da rede estadual (INEP, 2009).

Na sequência da análise, ficou demonstrado conforme a Figura 1. que 7(54\%) professores das escolas estaduais dispõem de mais de 2 horas na escola para planejar suas aulas, e 4(31\%) professores das escolas estaduais dispõem de 2 horas. Ficou evidenciado que $2(40 \%)$ professores das escolas particulares não apresentam nenhum tempo para planejamento das suas aulas na escola. Já os professores estaduais, apenas $15 \%$ deles não apresentam nenhum tempo. Este dado pode estar associado ao vínculo empregatício de cunho privado, sem estabilidade no emprego, que submete os professores das escolas particulares a um maior número de aulas do que os professores estaduais. Segundo Libâneo (1994) o planejamento tem grande importância por tratar-se de: "Um processo de racionalização, organização e coordenação da ação docente, articulando a atividade escolar e a problemática do contexto social" e de acordo com a LDBEN o professor tem a incumbência de não só ministrar os dias letivos e horas aulas estabelecidas, mas também participar de forma integral dos períodos dedicados ao planejamento.

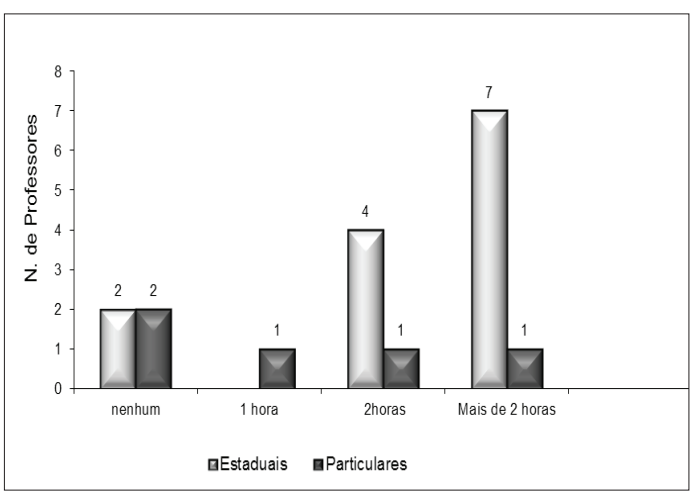

Fig.1. Tempo dedicado ao planejamento das aulas nas escolas estaduais e particulares

A Figura 2 expressa que 4(80\%) dos professores das escolas particulares realizam capacitação uma vez por ano. Já nas escolas estaduais, constatou-se que 10 professores (77\%) realizaram uma e/ou mais de uma capacitação por ano. E ainda indica que $4(30,8 \%)$ professores das escolas estaduais cursam duas vezes por ano e somente $2(15,4 \%)$ mais de duas vezes por ano. Porém nas escolas particulares apenas $1(20 \%)$ professor realiza mais de duas vezes por ano. Esse dado denota que tanto professores estaduais quanto particulares realizam curso de capacitação pelo menos uma vez por ano. Esse fato é relevante também nas palavras de Martins (2008), onde esclarece que os programas de formação continuada no Japão são obrigatórios durante todos os anos de profissão, até o momento da aposentadoria do educador. No entendimento de Selles (2002, p.13) a formação continuada de professores de Ciências, além de trazer consequências positivas no melhoramento de sua prática docente na atualização e ampliação dos conhecimentos específicos, induz a discussão sobre as questões educacionais, dentro do contexto de ensino. De acordo com Dias-da-Silva (1998), é preciso formar professores críticos e reflexivos, e capacitados para a construção da cidadania na sala de aula, somente assim, ocorrerá à transformação da escola.

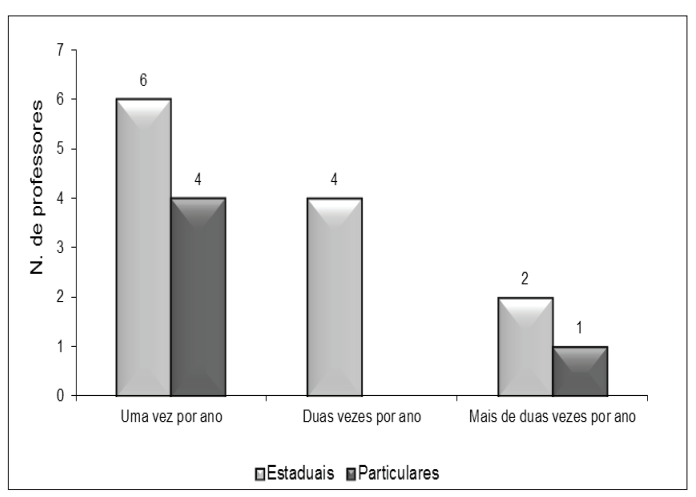

Fig. 2 Classificação quanto à frequência de capacitação em escolas estaduais e particulares 
$\mathrm{Na}$ investigação por titulação demonstrada na Figura 3, observou-se que 10 (77\%) dos professores das escolas estaduais responderam que concluíram curso de pós-graduação, sendo 8 destes (61,5\%) em nível de especialização lato sensu. Já nas escolas particulares $2(40 \%)$ dos professores concluíram especialização, demonstrando que os professores estaduais são mais qualificados que os das particulares. Em uma pesquisa realizada com professores de escolas municipais no Recife verificou-se que $35,7 \%$ dos entrevistados já possuíam algum curso de pós-graduação, sendo a maioria $(88,1 \%)$ com o nível de especialização lato sensu. (LIMA, 2008). Segundo dados do Censo Escolar da Educação Básica de 2009, o professor que atua no ensino médio apresenta a escolaridade mínima exigida pela atual legislação educacional, pois 360.577 professores têm curso superior com licenciatura, o que equivale a $87 \%$ do total. Dentre os outros, $6,4 \%$ $(53.978)$ possuem nível superior sem licenciatura e 6,6\% têm nível médio ou, apenas, fundamental. Os dados refletem o que Lima (2008) expõe sobre mudanças nas políticas públicas de incentivo aos professores, pois, a sobrecarga de trabalho aliado à remuneração precária, contribui para não seguir no nível de pós-graduação strito sensu.

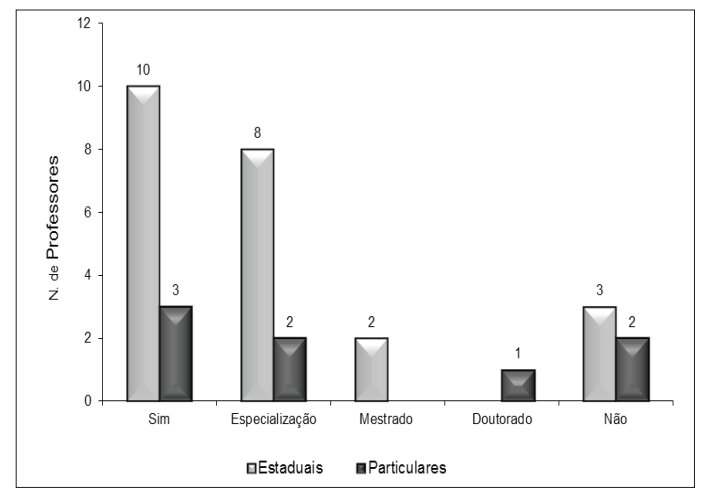

Fig. 3 Titulação dos professores das escolas estaduais e particulares

A Figura 4 indica o número de Escolas em que os professores lecionam. Constatou-se que $8(61,5 \%)$ dos professores estaduais lecionam em uma única escola e 2(15,3\%) em mais de duas escolas. Já os professores das escolas particulares $3(60 \%)$ lecionam em mais de duas escolas. Este dado pode estar relacionado com o fato de $40 \%$ dos professores particulares não apresentarem nenhum tempo para o planejamento de suas aulas. Segundo dados do Censo Escolar da Educação Básica de 2009 , no ensino médio a maioria dos professores $(86,7 \%)$ leciona em apenas uma escola.

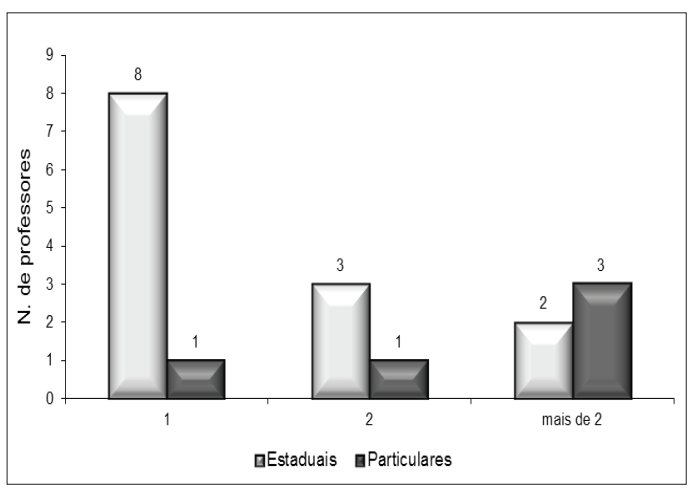

Fig. 4 Número de escolas em que os professores estaduais e particulares lecionam

Na segunda parte do questionário, relativo às questões abertas, categorizou-se as respostas dos Professores das Escolas Particulares e Estaduais por classes de palavras. Esta categorização está baseada na análise do conteúdo, nas questões abertas do questionário, e seguiu a classificação de Bardin (2004).

Tabela 1. Categorias obtidas pela análise de conteúdo das respostas segundo Bardin (2004).

\begin{tabular}{c|c|c}
\hline Categoria & Sigla & Descrição \\
\hline Cotidiano & CT & $\begin{array}{c}\text { Dia-a-dia, situações reais, } \\
\text { cotidiano, } \\
\text { teoria e prática, várias } \\
\text { formas e } \\
\text { maneiras, abordagem } \\
\text { diferentes, } \\
\text { realidade do aluno. }\end{array}$ \\
\hline Estratégia & ES & $\begin{array}{c}\text { Exemplos práticos, } \\
\text { diversificando } \\
\text { formas de fixação, } \\
\text { experiência do aluno, forma } \\
\text { oral e prática, } \\
\text { temas atuais. }\end{array}$ \\
\hline Conteúdo & CO & $\begin{array}{c}\text { Falta de conhecimento do } \\
\text { aluno e professor. }\end{array}$ \\
\hline Motivação & MO & Falta de interesse do aluno. \\
\hline Infra-Estrutura & IE & Falta de materiais. \\
\hline Tempo & TM & Carga-horária pequena. \\
\hline Positivo & PO & Sim e algumas vezes. \\
\hline Alimentos & AL & $\begin{array}{c}\text { Chocolates, refrigerantes, } \\
\text { iogurte. }\end{array}$ \\
\hline Medicamentos & ME & $\begin{array}{c}\text { Medicamentos, } \\
\text { plantas medicinais. }\end{array}$ \\
\hline Drogas ilícitas & DI & \begin{tabular}{c} 
Drogas. \\
\hline
\end{tabular}
\end{tabular}


As perguntas 1 e 2 do questionário, remetem as concepções prévias dos sujeitos sobre os conceitos e objetivos da contextualização. As análises das respostas obtidas focaram em duas questões: O que você entende por contextualização e qual é seu objetivo? A terceira pergunta teve a intenção de esclarecer a frequência sucedida pela contextualização em sala de aula, e as respostas vincularam-se a categoria Positivo (PO). Ficou demonstrado que $11(84,6 \%)$ dos professores estaduais agregaram seus conhecimentos prévios a categoria Cotidiano (CT), definida na Tabela 1, do mesmo modo ocorreu com os $5(100 \%)$ professores das escolas particulares, conforme demonstrado na Figura 5. Portanto, a contextualização no seu sentido mais amplo é pouco compreendida pela maioria dos professores, que detém uma visão limitada em apresentar o conteúdo relacionado "as coisas do cotidiano" e não objetiva a formação do aluno cidadão, habilitado na tomada de decisão sob a ótica CTSA. Esse dado reflete que a maioria dos professores associou a contextualização como uma simples exemplificação dos fatos do dia-a-dia, e está de acordo com as palavras de Silva (2009), que analisou três critérios na concepção de contextualização, como exemplificação de fatos do cotidiano, como estratégia de ensino aprendizagem e como desenvolvimento de atitudes e valores para formação do cidadão crítico e concluiu que $50 \%$ dos artigos sobre contextualização analisados no período entre 2000-2008 na Revista Química Nova abordavam o primeiro critério, ou seja, uma visão limitada, em que apenas os fatos do cotidiano são citados. A contextualização no ensino de ciências engloba competências de inserção da ciência e de suas tecnologias em um processo histórico, social e cultural e o reconhecimento e discussão de aspectos práticos e éticos da ciência no mundo contemporâneo (BRASIL, 2002). Nesta vertente de pensamento, Marcondes (2009) sugere que os conhecimentos científicos e tecnológicos devam propiciar o entendimento das questões sociais. Desse modo, a contextualização do ensino é tratada como fio condutor de uma educação para a cidadania na formação de cidadãos críticos.

Na terceira pergunta: Suas aulas de química são contextualizadas? A maioria respondeu afirmativamente $(\mathrm{PO})$, totalizando 12 professores das escolas estaduais e 5 das particulares, de acordo com a Figura 5. Nesta pergunta pode-se inferir que a totalidade dos respondentes considerou estar contextualizando os conteúdos, ainda que seja de uma maneira equivocada e segundo os seus conhecimentos prévios.

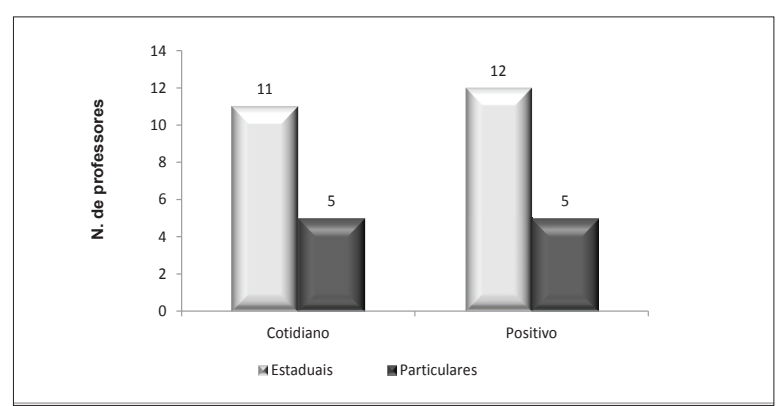

Fig.5 Categorias das respostas dos professores estratificadas sobre as perguntas: O que você entende por contextualização? Qual o objetivo da contextualização? Suas aulas de química são contextualizadas?

Na pretensão de conhecer um pouco mais sobre os temas relacionados à contextualização em sala de aula, foi solicitado citarem dois exemplos sobre contextualização na sexta pergunta. Os temas que mais sobressaíram foram alimentos, medicamentos e drogas ilícitas para ambas as classes de professores (Figura 6). A partir desses dados, deduziu-se que os temas relacionados à saúde são os mais procurados nas suas intervenções em sala de aula. Na visão de Ricardo (2007), é do exterior que devem surgir os temas, problemas, interesses e projetos, e aí sim buscar nos saberes disciplinares as prováveis respostas, para voltar ao exterior orientado. Neste aspecto, as estratégias (ES) desenvolvidas pelos professores em sala de aula, estão interligadas com os exemplos citados na questão 6 .

A quarta pergunta intencionava conceber as estratégias desenvolvidas pelos sujeitos na construção do conhecimento em sala de aula no modelo contextualizado: Como você trabalha a contextualização em sala de aula? Ficou evidenciado na Figura 6, que $11(84,6 \%)$ dos professores estaduais e $5(100 \%)$ dos professores particulares associaram a categoria Estratégia (ES), que utiliza exemplos práticos, temas atuais, dentre outras especificações da categoria, como estratégia de contextualização sem relacionar com a abordagem Ciência, Tecnologia, Sociedade e Ambiente. Esse dado demonstra o que já se suspeitava, de que as intervenções são pontuais e limitadas, sem recorrer a uma abordagem CTSA. Nessa vertente, Lima (2000) salienta que após a intervenção didática, ocorreu um enriquecimento nas respostas dos alunos e que é possível contextualizar. Esse aspecto pode ser comprovado por Medeiros (2010), no relato sobre as concepções prévias dos alunos sobre o tema radiações, percebeu que $82 \%$ dos alunos associavam esse tema ao malefício do homem e ao meio ambiente e, após o desenvolvimento do 
conteúdo contextualizado, essa proporção extinguiu-se, chegando a ultrapassar os muros escolares suscitando discussões entre amigos e familiares. A intervenção pedagógica está inserida entre momentos distintos, que representam o antes e o depois de sua realização e constituem as peças substanciais em toda prática educacional. O planejamento e a avaliação dos processos educacionais é uma parte inseparável da atuação docente. A própria intervenção pedagógica, leva em conta as intenções, as previsões, as expectativas e a avaliação dos resultados (ZABALA, 1998). Portanto, esta metodologia requer a intervenção do estudante em todo o processo de aprendizagem, fazendo as conexões entre os conhecimentos. Neste sentido, Wartha (2005) constatou que o ensino da química deve ir mais além do que leis e teorias, buscando formar um aluno cidadão para aprender a viver e atuar numa sociedade científica e tecnológica. De acordo com o MEC, esse aluno não será um expectador, um acumulador de conhecimentos, entretanto, será um agente transformador de si mesmo e do mundo, numa educação para a vida. Os contextos trabalhados terão significado para o aluno e o motivarão a aprender, num processo ativo, em que ele é protagonista. Desta forma, pensa-se que além do envolvimento intelectual, nasce o sentimento afetivo (MENEZES, 2002). Nessa perspectiva, constata-se o pensamento de Novak, de que o evento educativo é uma ação para trocar significados, se referindo também a uma troca de sentimentos, ou seja, o evento educativo é também acompanhado de uma experiência afetiva que está relacionada à predisposição para aprender (MOREIRA, 1995). A abordagem Ciência, Tecnologia, Sociedade e Ambiente revela a importância de ensinar a resolver problemas, confrontar pontos de vista e analisar criticamente argumentos, envolvendo atividades de investigação que privilegiem a integração e inter-relações CTSA (MARCONDES, 2009). Desse modo, a combinação da contextualização com a estratégia de ensino aprendizagem com o desenvolvimento para formação do cidadão crítico, seria ideal para o ensino de química, pois, além de proporcionar a compreensão dos conceitos químicos, desenvolveria atitudes e valores na formação do cidadão crítico atuante na sociedade (SILVA, 2009). Do mesmo modo Santos (2008) confirma que o objetivo final do ensino na perspectiva CTSA na educação básica é capacitar o aluno, que mais tarde será um cidadão letrado, na tomada de decisão e na participação da solução das questões locais de sua comunidade.

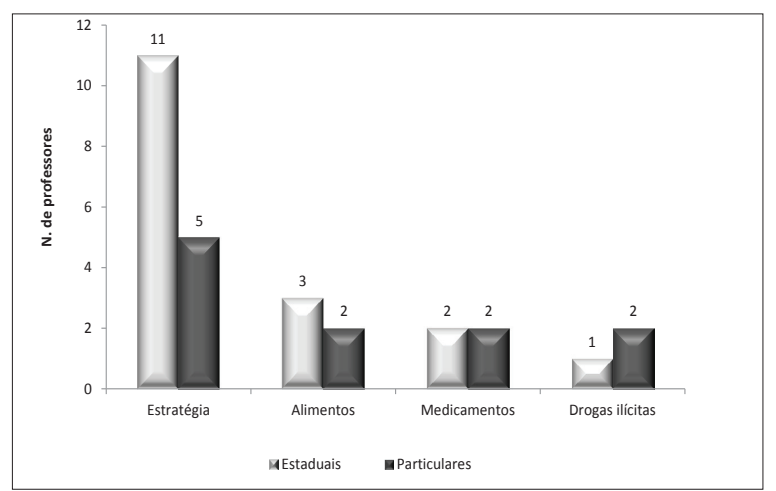

Fig.6 Categorias das respostas dos professores estratificadas sobre as perguntas: Como você trabalha a contextualização em sala de aula? Cite pelos menos dois exemplos sobre contextualização no ensino de química.

$\mathrm{Na}$ análise dos dados, verificou-se que 12(92,3\%) professores das escolas estaduais citaram as categorias Motivação (MO) e Tempo (TM) como as maiores dificuldades para contextualizar, seguido de $5(38,4 \%)$ professores que referiram-se a falta de Infra-Estrutura (IE) na escola, de acordo com a Figura 7. Estes números estão em consonância com os achados de Lima (2008, p.356) na entrevista com 42 professores, isto porque, 38(90,5\%) destacaram os pontos frágeis no desempenho docente estar atribuídos a falta de estratégias, ferramentas, conhecimento ou técnicas, aliados a falta de interesse e de disciplina dos alunos.

Muitas vezes um tema relevante para o professor não é para a comunidade escolar. Muitas vezes, evidencia-se que a falta de interesse dos alunos em sala de aula, se deve aos currículos defasados, falta de interações e enfoque CTSA. Por outro lado, enfatiza-se a necessidade de despertar no aluno a curiosidade, o espírito investigador, questionador e transformador da realidade para que aprenda a buscar a solução dos seus problemas e aplicá-los na prática diária (Pinheiro, 2007). Desse modo, sabe-se que o ensino e a aprendizagem na área de ciências têm apresentado problemas que precisam ser enfrentados, sendo que o enfoque apenas disciplinar ocasiona a desmotivação dos alunos. Nesse sentido, não corre a conexão entre a escola e as coisas do mundo, com a concepção de uma ciência e tecnologia neutra (Santos, 2008). 


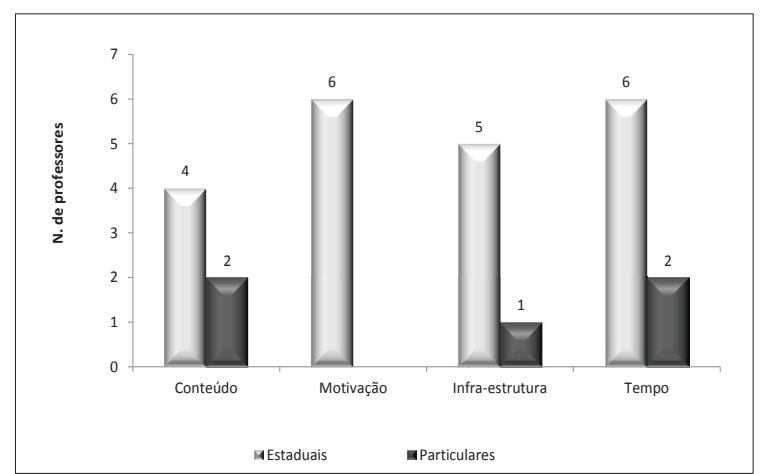

Fig.7 Categorias das respostas dos professores estratificadas sobre a pergunta: Quais as dificuldades que você encontra para contextualizar o conteúdo em sala de aula?

\section{CONSIDERAÇÕES FINAIS}

Antes de tudo, cabe ressaltar a importância do papel do professor como agente multiplicador do conhecimento e de sua determinante função na sociedade. Essa categoria profissional tão presente na formação profissional dos futuros cidadãos, tão necessária ao futuro de uma nação, demonstra algumas fragilidades nos dados apresentados neste trabalho. $\mathrm{O}$ pequeno incentivo financeiro à qualificação profissional, os baixos salários, a falta de políticas educacionais com perspectivas positivas, geram desmotivação à categoria. Desta forma, para conceber a complexidade do ensino atual e suas consequências em sala de aula, carece observar de forma holística todos os aspectos que circundam o educador no seu contexto de traba1ho. Muitas vezes, a contextualização não se faz presente em sala de aula devido ao pouco conhecimento, motivação e tempo no planejamento de ações educativas, pontos enfatizados através dos dados apresentados neste trabalho.

\section{REFERÊNCIAS}

ALARCÃO, Isabel. Professores reflexivos em uma Escola Reflexiva. Curitiba: Cortez. 2002.

AULER, D.; BAZZO.W.A. Reflexões para a Implementação do Movimento CTS no Contexto Educacional Brasileiro. Ciência \& Educação, v.7,n.1, p.1-13,2001.

AULER, D, et al. Abordagem Temática: natureza dos temas em Freire e no enfoque CTS. Alexandria Revista de Educação em Ciências e Tecnologia, v.2, n.1. p. 67-84, mar.2009.
BARDIN, L. Análise de Conteúdo. 3 ed. Lisboa: Edições 70, 2004.

BAZZO.W.A. Contexto da Educação Tecnológica. Ciência, Tecnologia e Sociedade. Florianópolis: editora da UFSM, 1998.

BRASIL. Ministério da Educação (MEC), Secretaria de Educação Média e Tecnológica (Semtec). PCN + Ensino Médio: orientações educacionais complementares aos Parâmetros Curriculares Nacionais - Ciências da Natureza, Matemática e suas Tecnologias. Brasília: MEC/Semtec, 2002.

CHASSOT, A, I. et. al. Química do Cotidiano: pressupostos teóricos para elaboração de material didático alternativo. Espaços da Escola, n.10, p. 47-53, 1993.

DIAS-DA-SILVA, M. H. G. F. O professor e seu desenvolvimento profissional: superando a concepção do algoz incompetente. Caderno CEDES, Campinas, v. 19, n. 44, p. 33-45, 1998.

Diretrizes e Bases da Educação Nacional, (Brasília) MEC, Art. 12-14. Estrutura e Funcionamento da Educação Básica. $2^{\circ}$ Ed., Editora: Pioneira. 2002.

FERREIRA, A.M.P.; FERREIRA. M.E.de M.P. A História da Ciência na Formação de Professores. História da Ciência do Ensino - Construindo Interfaces, vol.2, p.1-13, 2010.

FREIRE, P. Pedagogia da Autonomia: saberes necessários à prática educativa. São Paulo; Paz e terra, 2002.

GUIMARÃES, G.M.A et al. Modelos Didáticos no discurso de Professores de Ciências. Investigações em Ensino de Ciências, v.11, n.3, p.303-322, 2006.

INEP-MEC. Estudo exploratório sobre o professor brasileiro com base nos resultados do Censo Escolar da Educação Básica 2007/ Instituto Nacional de Estudos e Pesquisas Educacionais - Brasília: INEP, 2009.

KATO, D.S et al. As Concepções de Contextualização do Ensino em Documentos Curriculares Oficiais e de Professores de Ciências. Revista Ciência e Educação, v.17, n.1, p.35-50, 2011.

LIBÂNEO, J. C.. Didática. São Paulo. Editora Cortez. 1994. 
LIMA, K.E.C; VASCONCELOS, S.D. O professor de Ciências das Escolas Municipais de Recife e suas Perspectivas de Educação Permanente. Ciência \& Educação, v.14, n.2,p.347-364, 2008.

MARCONDES, M.E.R. et al. Materiais Instrucionais numa perspectiva CTSAA: Uma análise de unidades didáticas produzidas por professores de Química em formação continuada. Investigações em Ensino de Ciências, v.14(2), p.281-298, 2009.

MARTINS, A. R. Aprender sempre para ensinar mais. 2008. Disponível em: $<\underline{\text { http: } / / \text { edu- }}$ carparacrescer.abril.com.br/gestao-escolar/ capacitacao-professores-401074.shtml>. Acesso em: 20 de ago. de 2013.

MEDEIROS, M.A. et al. Contextualizando a Abordagem de Radiações no Ensino de Química Revista Ensaio: Pesquisa em Educação em Ciências, v.12, n.03, p.65-84, 2010.

MENEZES, Ebenezer Takuno de; SANTOS, Thais Helena dos, "Contextualização" (verbete). Dicionário Interativo da Educação Brasileira - EducaBrasil. São Paulo: Midiamix Editora, 2002, http://www.educabrasil.com.br/eb/ dic/dicionario.asp?id=55, Acesso em: 10 de ago de 2012.

MOREIRA, M, A. Monografia n.11 da Séries Enfoques Teóricos.Porto Alegre: Instituto de Física da UFRGS,1995.

Coletânea de breves monografias sobre teorias de aprendizagem como subsídio para o professor pesquisador, particularmente da área de ciências. $1^{\text {a }}$ ed., Porto Alegre, 2009.

MUENCHEN, C; AULER. D. Abordagem Temática: Desafios na Educação de jovens e adultos. Revista Brasileira de Pesquisa em Educação em Ciências, vol.7,n.3, 2007.

PÉREZ, D.G., C.P.M.A. Formação de professores de Ciências, $2^{\mathrm{a}}$ ed. Cortez: São Paulo, 1995.

PINHEIRO, N. A.M; Silveira, R. M. C.F; Bazzo, W. A. A relevância do enfoque CTS para contexto do ensino médio. Ciência, Tecnologia e Sociedade, v.13, n 1-5, 2007.

RICARDO, E.C. Educação CTSA: Obstáculos e Possibilidades para sua Implementação no
Contexto Escolar. Ciência \& Ensino, vol.1. número especial, novembro de 2007.

SANTOS, W.L.P Dos. Educação Científica Humanística em Uma Perspectiva Freireana: Resgatando a Função do Ensino de CTS. Alexandria Revista de Educação em Ciência e Tecnologia, v.1,n.1, p.109-131, mar. 2008.

SELLES, S.E. Formação Continuada e Desenvolvimento Profissional de Professores

de Ciências: Anotações de um Projeto. ENSAIO - Pesquisa em Educação em Ciências. v. 02, n. 2, Dez. 2002.

SILVA, R.T. et al. Contextualização e Experimentação Uma Análise dos Artigos Publicados na seção "Experimentação no Ensino de Química" da Revista Química Nova na Escola 2002008. Revista Ensaio: Pesquisa em Educação em Ciências, v.11, n.2, 2009.

WARTHA, E, J,; ALÁRIO. A.F. A contextualização no Ensino de Química através do Livro Didático. Química Nova na Escola. , n.22, nov., 2005.

ZABALA, A. A prática Educativa como Ensinar. Artmed: Porto Alegre, 224p, 1998.

ZANELLA, L.C.H. Metodologia de estudo e de pesquisa em Administração. Florianópolis: Departamento de Ciências da Administração/ UFSC; Brasília: CAPES: UAB, 164p., 2009. 